\title{
Electropolymerization of Azure A and pH Sensing Using Poly(azure A)-modified Electrodes
}

\author{
Kyoko Sugiyama, ${ }^{*}$ Kazuhiro Watanabe, ${ }^{* \dagger}$ Sachiko Komatsu,* Kentaro Yoshida, ${ }^{* *}$ Tetsuya Ono,** \\ Tsutomu FujImURa, ${ }^{*}$ Yoshitomo KaShIWAGI, $* *$ and Katsuhiko SATO $* * * * \dagger$ \\ *Faculty of Pharmaceutical Science, Tohoku Medical and Pharmaceutical University, 4-4-1 Komatsushima, \\ Aoba, Sendai, Miyagi 981-8558, Japan \\ **School of Pharmaceutical Sciences, Ohu University, 31-1 Misumido, Tomita-machi, Koriyama, \\ Fukushima 963-8611, Japan \\ ***Department of Creative Engineering, National Institute of Technology, Tsuruoka College, 104 Sawada, \\ Inooka, Tsuruoka, Yamagata 997-8511, Japan
}

\begin{abstract}
A modified electrode was developed by immobilizing poly(azure A) (pAA) onto the surface of a glassy carbon electrode via the electropolymerization of azure A (AA). The pAA immobilized on the electrode exhibited redox response during cyclic voltammetry (CV) and differential pulse voltammetry (DPV). The redox reaction obeyed the Nernst equation because of the involvement of $\mathrm{H}^{+}$ions. In addition, the peak potential was shifted according to the solution $\mathrm{pH}$. The shifts of the oxidation peak potential could be more easily observed using DPV than when using CV, indicating that the developed electrode could be useful as a $\mathrm{pH}$ sensor. This $\mathrm{pH}$ measurement method can be successfully applied in the $\mathrm{pH}$ range of 1 to 10 and can be successfully repeated more than 50 times.
\end{abstract}

Keywords pH sensor, electropolymerization, azure A, methylene blue

(Received September 15, 2020; Accepted October 22, 2020; Advance Publication Released Online by J-STAGE October 30, 2020)

\section{Introduction}

The $\mathrm{pH}$ level is one of the most important properties associated with an aqueous solution. There are various methods for measuring the $\mathrm{pH}$ depending on the type of the sample and the purpose of use, including using a glass membrane electrode, an ion-sensitive field-effect transistor (ISFET), $\mathrm{pH}$ indicator dyes, and a fluorescent probe. Among those methods, the currentmeasuring electrochemical method is characterized by its low cost, simple operation, and ease of developing an electrode. Therefore, it can be applied to develop simple sensors. ${ }^{1-4}$ Because of the aforementioned advantages, various studies have investigated methods to measure $\mathrm{pH}$ based on electric current. ${ }^{5-10}$

Therefore, we decided to use azure A (AA), which is considered an analogue of methylene blue (MB) (Fig. 1). The peak potential associated with the redox reaction of MB shifts according to the $\mathrm{pH}$ changes. ${ }^{11,12}$ In addition, another study has investigated intracellular $\mathrm{pH}$ measurements using a $\mathrm{MB}$ solution. ${ }^{13}$ We attempted to develop an electrode via the electropolymerization of AA. AA can be easily immobilized as poly(azure A) (pAA) on an electrode surface via electropolyme rization. ${ }^{14-17} \mathrm{MB}$ immobilized electrodes can be prepared by electrochemical polymerization. However, we decided to use $\mathrm{AA}$ as a $\mathrm{pH}$ probe to compare with the method of immobilization

$\dagger$ To whom correspondence should be addressed. E-mail: k-nabe@ tohoku-mpu.ac.jp (K. W.); satok@tohoku-mpu. ac.jp (K. S.) on a multilayer film via a primary amine of AA. ${ }^{10}$ The AA immobilized on the electrode surface showed a $\mathrm{pH}$-dependent redox response similar to that exhibited by $\mathrm{MB}$, as well as a good response in the $\mathrm{pH}$ range of 1 to 10 .

\section{Materials and Methods}

A pAA-modified electrode was prepared via the electropolymerization of AA as described below. A glassy carbon (GC) electrode having a diameter of $3 \mathrm{~mm}$ was polished using $1-\mu \mathrm{m}$ alumina and then immersed in $1 \mathrm{mM}$ AA solution ( $\mathrm{pH} 3$ ), which was prepared by dissolving AA (Tokyo Chemical Industry Co.) in $100 \mathrm{mM}$ phosphate buffer solution. Thereafter, the AA was polymerized on the electrode via CV (sweep potential: approximately $0.8-1.2 \mathrm{~V}$, sweep speed: $50 \mathrm{mV} / \mathrm{s}$, and number of cycles: 2).

$\mathrm{CV}$ and DPV were conducted using an electrochemical analyzer (ALS Model 660B; BAS, Tokyo, Japan) in a conventional three-electrode cell comprising a pAA-modified electrode as the working electrode, a platinum wire as the counter electrode, and $\mathrm{Ag} / \mathrm{AgCl}\left(3 \mathrm{~mol} \mathrm{~L}^{-1} \mathrm{KCl}\right)$ as the reference electrode. The DPV parameters applied included a step potential of $4 \mathrm{mV}$, pulse amplitude of $50 \mathrm{mV}$, pulse width of $60 \mathrm{~ms}$, pulse period of $200 \mathrm{~ms}$, sample period of $20 \mathrm{~ms}$, and voltage range of $-0.6-0.4 \mathrm{~V}$. All measurements were performed multiple times, and the average values were plotted. 
<smiles>CN(C)c1ccc2nc3ccc(=[N+](C)C)cc-3sc2c1</smiles>

Methylene blue

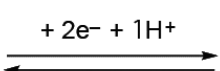<smiles>CN(C)c1ccc2c(c1)Sc1cc(N(C)C)ccc1N2</smiles>

Leucomethylene blue

Fig. 1 Structure and redox reaction of methylene blue (MB).
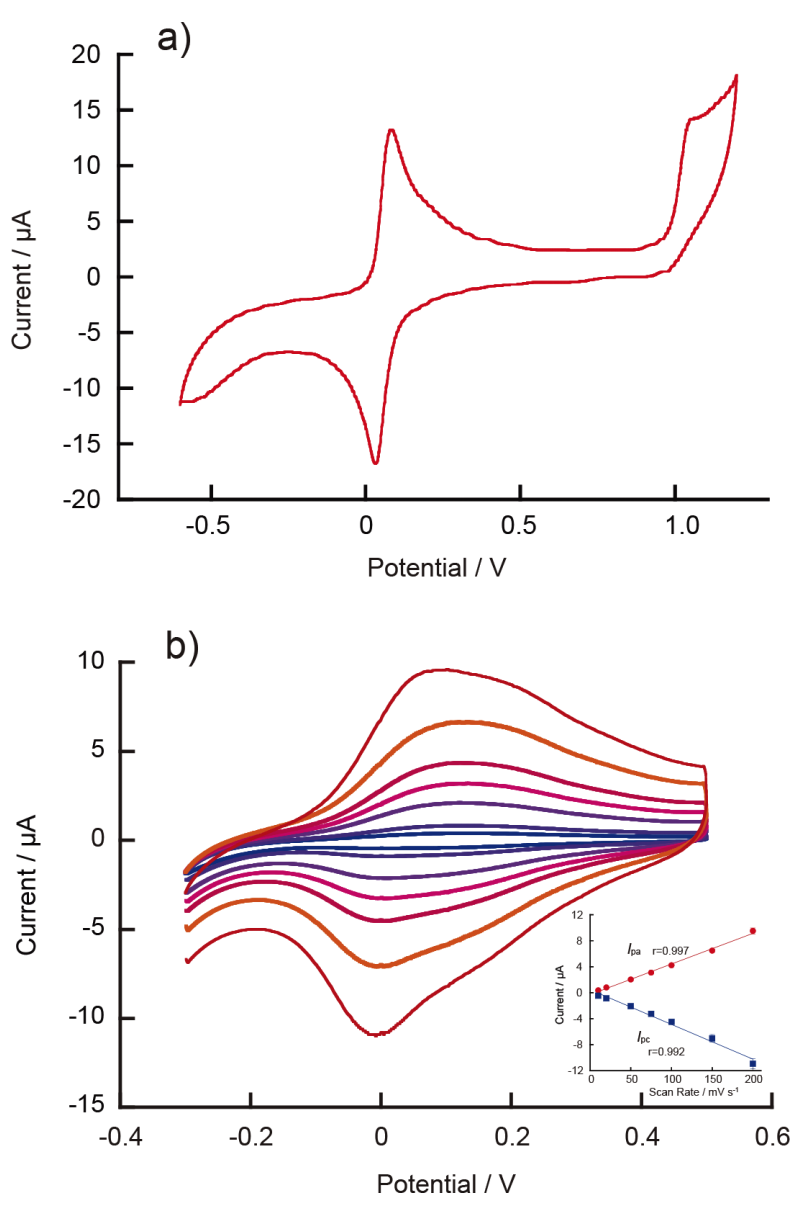

Fig. 2 (a) Cyclic voltammogram of electropolymerization of azure A (1 mM, pH 3.0) with a glassy carbon (GC) electrode (3-mm diameter). (b) Cyclic voltammograms of poly(azure A)-modified electrode (3-mm diameter in a $100 \mathrm{mM}$ phosphate buffer solution (pH 3.0) at different scan rates of 10, 20, 50, 75, 100, 150, and $200 \mathrm{~m} \mathrm{~V} \mathrm{~s}^{-1}$. Insert: Plots of the anodic peak current $\left(I_{\mathrm{pa}}\right)$ and the cathodic peak current $\left(I_{\mathrm{pc}}\right)$ vs. the scan rate.

\section{Results and Discussion}

The probe was immobilized onto the electrode to ensure easy application as an electrochemical sensor. Various methods have been proposed for the immobilization of a probe on a solid surface, including the bindinf of the pendant groups on a polyelectrolyte via covalent bonds ${ }^{18,19}$ and the self-assembled monolayer method. ${ }^{20,21}$ In this study, we attempted to immobilize pAA onto an electrode via the electrochemical oxidation of AA. ${ }^{14-17}$ Figure 2 a shows the voltammogram of polymerization in the case of $1 \mathrm{mM} \mathrm{AA}$ (prepared with $100 \mathrm{mM}$ phosphate buffer solution) at $\mathrm{pH} 3$. A reversible redox reaction of the AA was observed with a reduction peak of $0.031 \mathrm{~V}$ and oxidation peaks of approximately 0.082 and $1 \mathrm{~V}$. The oxidation peak was observed at $1 \mathrm{~V}$, indicating that the polymerization of $\mathrm{AA}$ progressed at the electrode surface and that pAA was immobilized (Fig. 3). The CV scans of the pAA-modified electrode at various scan rates in PBS at $\mathrm{pH} 3.0$ were performed and the results are shown in Fig. 2(b). The results indicated that the anodic and cathodic peak currents are directly proportional to the scan rate, and that AA was immobilized on the electrodes surface by electrolytic polymerization. Similar results have been obtained in previous works. ${ }^{11}$ Furthermore, the polymerization of AA was observed even if polymerization was similarly conducted in a phosphate buffer at $\mathrm{pH} 5,7$, and 9 . In the following experiments, based on the good reproducibility of the resultant voltammograms, we performed the electrolytic polymerization of AA for performing $\mathrm{pH}$ measurements using $1 \mathrm{mM}$ AA solution prepared in a $100 \mathrm{mM}$ phosphate buffer solution.

After the preparation of the pAA-modified electrode (3-mm diameter), $\mathrm{CV}$ measurements were conducted in a phosphate buffer solution (100 mM) at $\mathrm{pH} 1$ to 13 (Fig. 4a). During CV measurement, the peak oxidation potentials were $0.25 \mathrm{~V}$ at $\mathrm{pH} 1$ and $-0.22 \mathrm{~V}$ at $\mathrm{pH} 13$, suggesting a negative potential shift with increasing basicity. The peak reduction potentials were $0.17 \mathrm{~V}$ at $\mathrm{pH} 1$ and $-0.20 \mathrm{~V}$ at $\mathrm{pH} 8$, which also indicated a negative potential shift with increasing basicity. However, the peak potential was not clear at $\mathrm{pH} 8.5$ - 13.5 because of the reduction current of oxygen. By plotting the peak potentials observed in case of oxidation and reduction against the $\mathrm{pH}$, linear changes can be observed with respect to the peak potentials depending on the $\mathrm{pH}$ change in the $\mathrm{pH}$ range of $1-10$ (Fig. $4 \mathrm{~b}$ ). Based on the calibration curves obtained from the potential peaks during oxidation and reduction, the potential shifts per unit of $\mathrm{pH}$ change in the oxidation and reduction peaks were 46 and $59 \mathrm{mV}$, respectively, and the correlation coefficients were 0.995 for both the cases.

For DPV using a pAA-immobilized electrode, $\mathrm{pH}$ measurements were conducted based on the peak shifts in the oxidation potential. As a result, similar to $\mathrm{CV}$, the peak potentials were $0.24 \mathrm{~V}$ at $\mathrm{pH} 1$ and $-0.38 \mathrm{~V}$ at $\mathrm{pH} 13$, indicating a negative shift of the peak potential with increasing basicity (Fig. 5a). The current values increased under strong base and strong acidic $\mathrm{pH}$ conditions. The same trend was observed in the DPV measurement of methylene blue, ${ }^{10}$ although the cause was unknown. The peak potentials in DPV could be more easily determined when compared with those in CV. Therefore, the measurement can be easily performed using DPV. Figure $5 b$ presents a plot of the peak potentials $v s$. $\mathrm{pH}$, suggesting that DPV can be used for $\mathrm{pH}$ sensing similar to CV. Based on the slope in Fig. 5b, the peak potential shift was $55 \mathrm{mV}$ when the $\mathrm{pH}$ value was changed by 1 within the $\mathrm{pH}$ range of $1-10(R=$ 0.995). $\mathrm{pH}$ sensing based on DPV measurements was investigated through the following experiments.

Then, the durability of the modified electrode as a $\mathrm{pH}$ sensor was evaluated. The microfabricated electrochemical sensors, which can be repeatedly used, can be applied to various fields, including real-time monitoring and imaging., ${ }^{4,20}$ The durability 


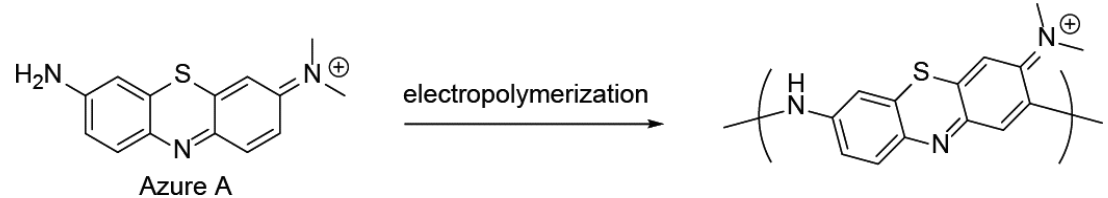

Fig. 3 Structure and electropolymerization of azure A.

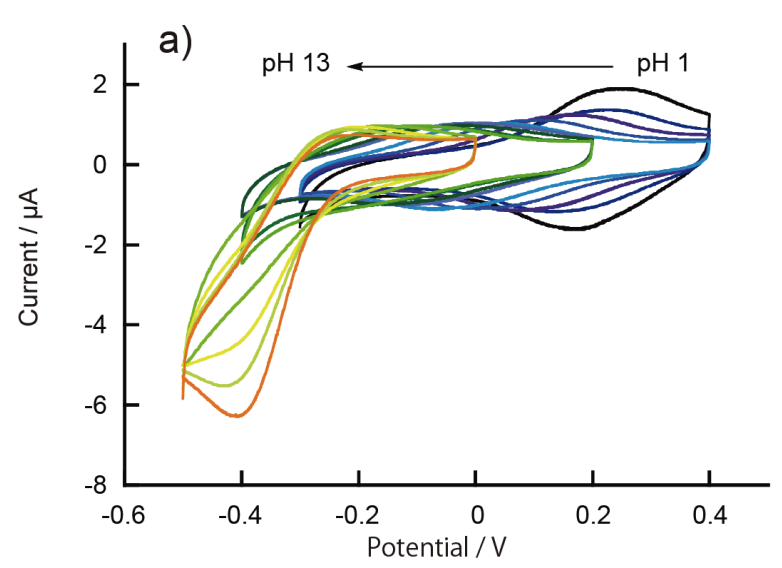

b)

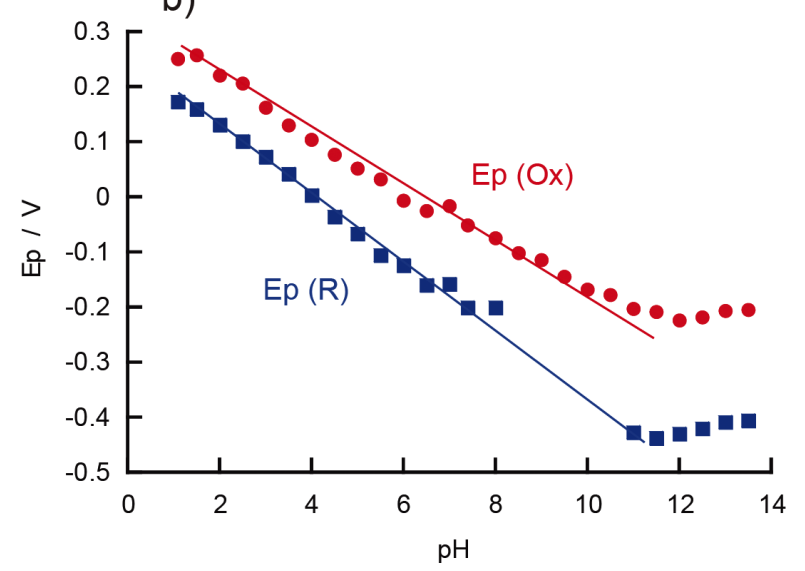

Fig. 4 (a) Cyclic voltammograms of the poly(azure A)-modified glassy carbon (GC) electrode (3-mm diameter) in a $100 \mathrm{mM}$ phosphate buffer solution at $\mathrm{pH} 1.1-13.5$. (b) Plots of oxidation and reduction peak potentials $v s$. $\mathrm{pH}$.

of the pAA-modified GC electrode was evaluated by repeating the DPV measurements in a phosphate buffer solution $(100 \mathrm{mM})$ at $\mathrm{pH} 3,7.4$, and 9. The peak potential did not change after 50 measurements, indicating that the pAA-modified GC electrode can be repeatedly used (Fig. 6). The pAA current decreased with each measurement because the pAA on the electrode gradually became electrochemically inactive after each measurement. Therefore, almost no oxidation current was observed after the 50th measurement, and it became difficult to detect any peak potential.

We also studied the influence of additives on the pAAimmobilized electrode. DPV was conducted in a phosphate buffer solution $(100 \mathrm{mM})$ containing glucose, glutamic acid, ascorbic acid $(10 \mathrm{mM})$, or $\mathrm{NaCl}(1 \mathrm{M})$, and the peak potentials were plotted against the $\mathrm{pH}$ (Fig. 7). The peak oxidation potential of the pAA-modified electrode was $-0.165 \mathrm{~V}$ at $\mathrm{pH} 7.4$ condition (control). The oxidation potential of the pAA-

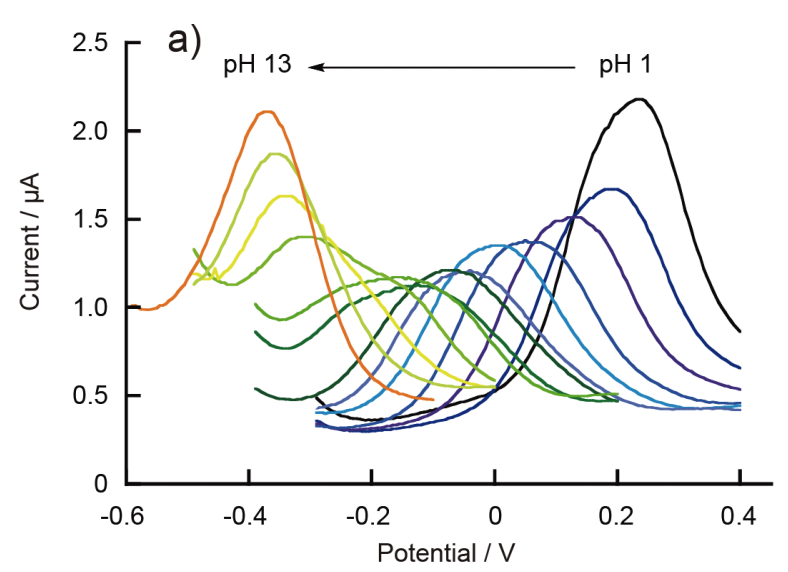

b)

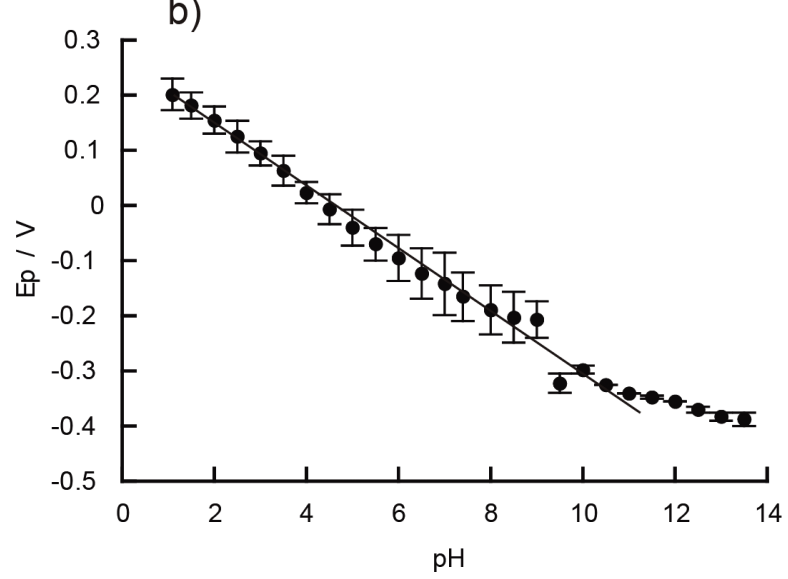

Fig. 5 (a) Differential pulse voltammetry (DPV) measurement using a poly(azure A)-modified glassy carbon (GC) electrode (3-mm diameter) in $100 \mathrm{mM}$ phosphate buffer solution at $\mathrm{pH} 1.1-13.5$. (b) Plot of peak potential vs. $\mathrm{pH}$.

modified electrode was shifted to -0.110 and $-0.105 \mathrm{~V}$ by the addition of glucose and glutamate, respectively. Perhaps the interaction of these molecules with the secondary amines in the pAA structure shifted the oxidation potential. This $\mathrm{pH}$ measurement was also slightly affected by the ionic strength. A strong influence could be observed when ascorbic acid was added, i.e., the oxidation potential shifted by approximately $200 \mathrm{mV}$ at $\mathrm{pH}$ 5. This can be attributed to the reduction ability of ascorbic acid. We speculate that the reduction effect of the ascorbic acid affected peak potential shift more than anion doping. Therefore, pretreatment with ascorbate oxidase or similar materials may be required for analyzing samples containing ascorbic acid. 


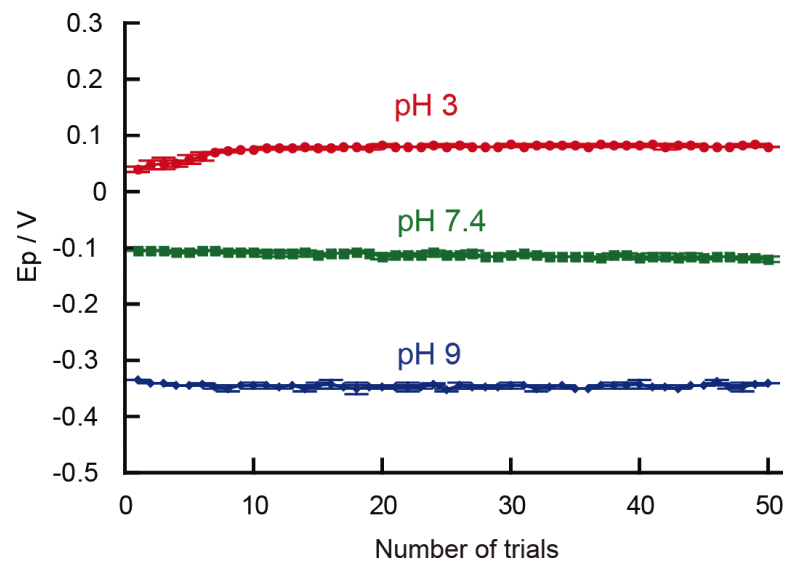

Fig. 6 Peak potential changes associated with the repeated differential pulse voltammetry (DPV) measurements in a phosphate buffer solution (100 mM) at $\mathrm{pH} \mathrm{3,} 7.4$ and 9 using the poly(azure A)modified glassy carbon (GC) electrode (3-mm diameter).

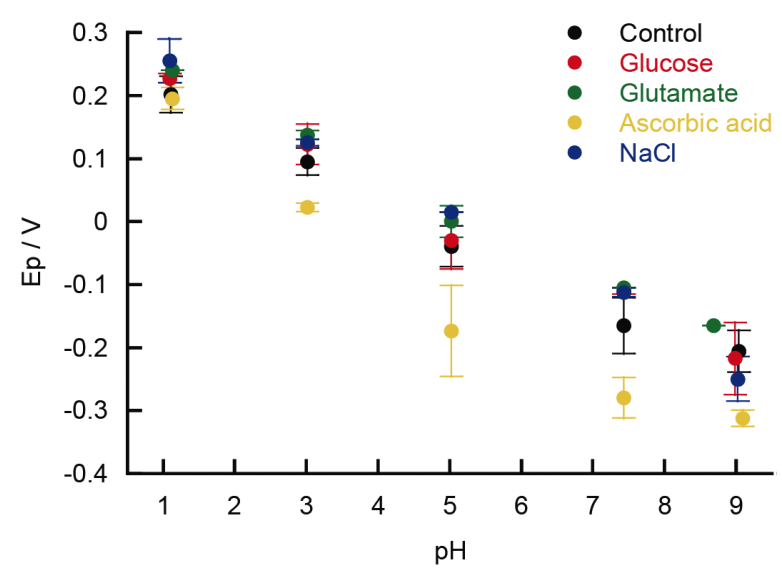

Fig. 7 Plot of peak potentials vs. $\mathrm{pH}$ for differential pulse voltammetry (DPV) measurements in a phosphoric acid solution $(100 \mathrm{mM})$ containing either glucose, glutamic acid, ascorbic acid $(10 \mathrm{mM})$, or $\mathrm{NaCl}(1 \mathrm{M})$ using a poly(azure A)-modified electrode (3-mm diameter).

\section{Conclusions}

A pAA-modified electrode was successfully developed via the electropolymerization of AA. Based on the CV and DPV measurements, the peak potential of the pAA-immobilized electrode shifted with the change in $\mathrm{pH}$. Although the measurement was slightly influenced by additives, the electrode exhibited durability for 50 or more measurements. We immobilized pAA on a multilayer film via a primary amine of $\mathrm{AA}$ and performed similar $\mathrm{pH}$ measurements. ${ }^{23}$ In comparison, this method could be applied measure $\mathrm{pH}$ in a wide range, although it was slightly affected by coexisting substances. In addition, the apparatus required to develop the electrode was the same as that required for performing the $\mathrm{pH}$ measurements. Furthermore, the polymerization and measurement of AA was completed within minutes and seconds, respectively. Therefore, $\mathrm{pH}$ can be easily measured using this type of pAA-modified electrode.

\section{Acknowledgements}

This work was supported by Tohoku Medical and Pharmaceutical University, which was partially supported by a Japan Society for the Promotion of Science (JSPS), Grant-in-Aid for Scientific Research (C) (No. 19K08663 and 16K08173) (K. W.) and (No. 20K06984) (K. S.).

\section{References}

1. K. Sato, T. Ono, K. Yoshida, and T. Ito, Electroanalysis, 2015, 27, 2272.

2. T. Minamiki, S. Tokito, and T. Minami, Anal. Sci., 2019, 35, 103.

3. T. Shimada, H. Yasaki, T. Yasui, T. Yanagida, N. Kaji, M. Kanai, K. Nagashima, T. Kawai, and Y. Baba, Anal. Sci., 2018, 34, 1347.

4. K. Sato, T. Kamijo, S. Takahashi, and T. Sato, Electroanalysis, 2018, 30, 2237.

5. B. P. Nadappuram, K. McKelvey, R. A. Botros, A. W. Colburn, and P. R. Unwin, Anal. Chem., 2013, 85, 8070.

6. K. Chaisiwamongkhol, C. Batchelor-McAuley, and R. G. Compton, Analyst, 2019, 144, 1386.

7. C.-M. Yanga, T.-W. Chiang, Y.-T. Yeh, A. Das, Y.-T. Lin, and T.-C. Chen, Sens. Actuators, B, 2015, 207, 858.

8. S. Pöller and W. Schuhmann, Electrochim. Acta, 2014, 140, 101.

9. M. Amiri, E. Amali, A. Nematollahzadeh, and H. Salehniya, Sens. Actuators, B, 2016, 228, 53.

10. K. Watanabe, K. Sugiyama, S. Komatsu, K. Yoshida, T. Ono, T. Fujimura, Y. Kashiwagi, and K. Sato, Polymers, 2020, 12, 2328.

11. T. Sagara, J. Iizuka, and K. Niki, Langmuir, 1992, 8, 1018.

12. N. Leventis and M. Chen, Chem. Mater., 1997, 9, 2621.

13. L. Ning, X. Li, D. Yang, P. Miao, Z. Ye, and G. Li, Anal. Chem., 2014, 86, 8042.

14. T. Liu, Y. Luo, W. Wang, L. Kong, J. Zhu, and L. Tan, Electrochim. Acta, 2015, 182, 742.

15. K. Piwowar, A. Blacha-Grzechnik, R. Turczyn, and J. Zak, Electrochim. Acta, 2014, 141, 182.

16. T. Liu, Y. Luo, L. Kong, J. Zhu, W. Wang, and L. Tan, Sens. Actuators, B, 2016, 235, 568.

17. C. Chen and S. Mu, J. Appl. Polym. Sci., 2003, 88, 1218.

18. K. Sato, M. Takahashi, M. Ito, E. Abe, and J. Anzai, Langmuir, 2014, 30, 9247.

19. K. Sato, M. Takahashi, M. Ito, E. Abe, and J. Anzai, J. Mater. Chem. B, 2015, 3, 7796 .

20. D. Zhao, H. Tang, H. Wang, C. Yang, and Y. Li, ACS Sens., 2020, 5, 2177.

21. Q. Cheng and A. Brajter-Toth, Anal. Chem., 1996, 68, 4180.

22. H. Shiku, Anal. Sci., 2019, 35, 29.

23. Y. Takahashi, A. Kumatani, H. Shiku, and T. Matsue, Anal. Chem., 2017, 89, 342. 